\title{
Regional Flaps in Coverage of Facial Defects: Our Experience
}

\author{
BELAL A. ALMOBARAK, M.D., M.R.C.S.; MOHAMED ELSAYED MOHAMED, M.D.; \\ MOHAMED IBRAHIM HASSAN, M.D. and MOHAMED OSAMA KOTB, M.D.
}

The Department of Plastic Surgery, Ahmed Maher Teaching Hospital, Cairo, Egypt

\section{INTRODUCTION}

Reconstruction of acquired defects of the face remains one of the most challenging tasks for the reconstructive surgeon [1].

There are several reconstructive options for facial defects including primary repair, skin grafts, local flaps, regional flaps, or distant and free flaps. The choice of reconstructive procedure depends on several factors including size, location, and involvement of deeper structures [2].

Reliable and simultaneous reconstruction of head and neck defects has been made possible by the development and application of different flap techniques. It is possible to reconstruct most defects immediately, which leads to better restoration of form and function (when rehabilitation takes place early) [3].

By the end of the 1980s and the beginning of the 1990s, free flaps became popular, and pedicled regional flaps were used with decreasing frequency. In many instances, pedicled regional or microvascular soft tissue flaps compete for the same indication, each technique with its advantages and disadvantages [4].

Larger defects require transfer of more distant soft tissue sources, such as the cervico-facial, cervico-pectoral, delto-pectoral, or pectoralis major flap [5].

For defects of the nose the "workhorse" of reconstruction including reconstruction of total nasal loss is the midline forehead flap, while defects of the Alar area may be repaired with superiorly based nasolabial flaps [6].

\section{MATERIAL AND METHODS}

At the Plastic Surgery Department of Ahmed Maher Teaching hospital, from January 2010 to December 2014 we used 43 several flaps for reconstructing different facial defects caused by trauma (of different types) or malignancy. Demographic data, causes and sites of defects were analysed.

The flaps harvested varied according to the site of defect. Flaps used were delto-pectoral (DPF), pectoralis Major myo-cutaneous flap (PMMF), cervico-facial(CFF), cervico-pectoral (CPF), medline forehead flap (MFF), and nasolabial flap (NLF).

Some flaps needed a second stage for division 3 weeks after the time of reconstruction (deltopectoral flap, Midline forehead flap, and some nasolabial flaps). The size of the harvested flap, the harvesting time, results of flap transfers, and flap-related complications were analysed. Severe complication was defined as more than one-fourth to total loss of the flap. A moderate complication was defined as loss of less than one-fourth of the entire flap. A fistula, epidermolysis, dehiscence, or hematoma leading to impairment of wound healing was defined as a minor complication.

\section{RESULTS}

Patient data are summarized in Table (1).

43 patients ( 33 males and 10 females) underwent reconstruction of different facial defects using 43 different flaps. The facial defects involved the nose, perioral area, lower lip, upper lip, mandibular area, lateral side of face, cheeks, orbital and max- 
illary areas caused by malignancy trauma, burn, or human or animal bites.

Characteristics of the flaps transferred are shown in Table (2).

The average times of flap harvest were between 20 minutes to 90 minutes according to the type of the flap (the shortest time was that for the nasolabial flap while the longest was that for pectoralis major myo-cutaneous flap).
Mean flap sizes ranged from $10 \mathrm{~cm}^{2}$ (nasolabial flap) to $150 \mathrm{~cm}^{2}$ (PMMF).

The overall Complications occurred in $10 \mathrm{pa}-$ tients (9 minor and 1 moderate) represented $23.26 \%$, the specific numbers are shown in Table (2). The remaining patients showed no complications and passed an uneventful follow-up period representing $76.74 \%$.

Mean follow-up periods were about 6 to 12 months in all types of flaps.

Table (1): Summary of patients.

\begin{tabular}{|c|c|c|c|c|c|c|}
\hline Type of flap & $\begin{array}{l}\text { DPFF } \\
(\mathrm{n}=10)\end{array}$ & $\begin{array}{c}\text { PMMF } \\
(n=6)\end{array}$ & $\begin{array}{l}\text { CFF } \\
(n=6)\end{array}$ & $\begin{array}{c}\text { CPF } \\
(n=4)\end{array}$ & $\begin{array}{c}\text { MFF } \\
(n=10)\end{array}$ & $\begin{array}{l}\text { NLF } \\
(n=7)\end{array}$ \\
\hline \multicolumn{7}{|l|}{ Patients (n): } \\
\hline Male (n) & 7 & 5 & 4 & 4 & 7 & 6 \\
\hline Female (n) & 3 & 1 & 2 & - & 3 & 1 \\
\hline \multicolumn{7}{|l|}{ Diagnosis: } \\
\hline Tumors & 7 & 5 & 6 & 2 & 6 & 4 \\
\hline Trauma & 2 & 1 & - & - & 2 & 2 \\
\hline Burn & 1 & - & - & 2 & 1 & 1 \\
\hline Human or animal bites & - & - & - & - & 1 & - \\
\hline \multicolumn{7}{|l|}{ Area reconstructed: } \\
\hline Nose & 1 & - & - & - & 10 & 7 \\
\hline Perioral area & 3 & 2 & - & - & - & - \\
\hline Lower lip & 2 & - & - & - & - & - \\
\hline Upper lip & - & - & - & - & - & - \\
\hline Mandibular area & 2 & 2 & - & - & - & - \\
\hline Lateral side of face & - & - & 1 & 3 & - & - \\
\hline Cheeks & 2 & 1 & 4 & 1 & - & - \\
\hline Orbito-maxillary & - & 1 & 1 & - & - & - \\
\hline $\begin{array}{l}\text { (N): Number of patients. } \\
\text { (DPF): Delto-pectoral flap. } \\
\text { (PMMF): Pectoralis major myo }\end{array}$ & flap. & $\begin{array}{l}\text { (CFF): } \mathrm{Cer} \\
\text { (CPF): } \mathrm{Cer}\end{array}$ & $\begin{array}{l}\text { al flap. } \\
\text { toral flap. }\end{array}$ & $\begin{array}{l}\text { (MF } \\
\text { (NL }\end{array}$ & $\begin{array}{l}\text { ie forehea } \\
\text { bial flap. }\end{array}$ & \\
\hline
\end{tabular}

Table (2): Characteristics of the flaps.

\begin{tabular}{|c|c|c|c|c|c|c|}
\hline Type of flap & $\begin{array}{l}\text { DPFF } \\
(\mathrm{n}=10)\end{array}$ & $\begin{array}{c}\text { PMMF } \\
(\mathrm{n}=6)\end{array}$ & $\begin{array}{l}\text { CFF } \\
(n=6)\end{array}$ & $\begin{array}{l}\mathrm{CPF} \\
(\mathrm{n}=4)\end{array}$ & $\begin{array}{c}\text { MFF } \\
(n=10)\end{array}$ & $\begin{array}{l}\text { NLF } \\
(n=7)\end{array}$ \\
\hline Estimated flap size $\left(\mathrm{cm}^{2}\right)$ & $20-40$ & $100-150$ & Up to 120 & Up to 120 & Up to 50 & Up to 20 \\
\hline Estimated harvest time (min) (mean) & 45 & 90 & 45 & 60 & 30 & 20 \\
\hline Outcome of flaps transferred & - & - & - & - & - & - \\
\hline Severe complications & - & 1 & - & - & - & - \\
\hline Moderate complications & - & 2 & - & 2 & 2 & - \\
\hline Minor complications & 2 & - & 1 & - & - & - \\
\hline
\end{tabular}

(N): Number of patients.

(DPF): Delto-pectoral flap.

(CFF): Cervico-facial flap.

(CPF): Cervico-pectoral flap.

(MFF): Midline forehead flap.

(PMMF): Pectoralis major myo-cutaneous flap. 
(A)

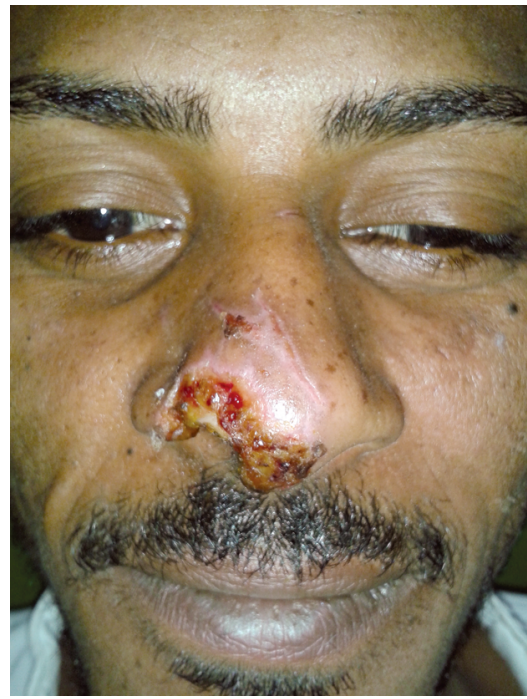

(C)

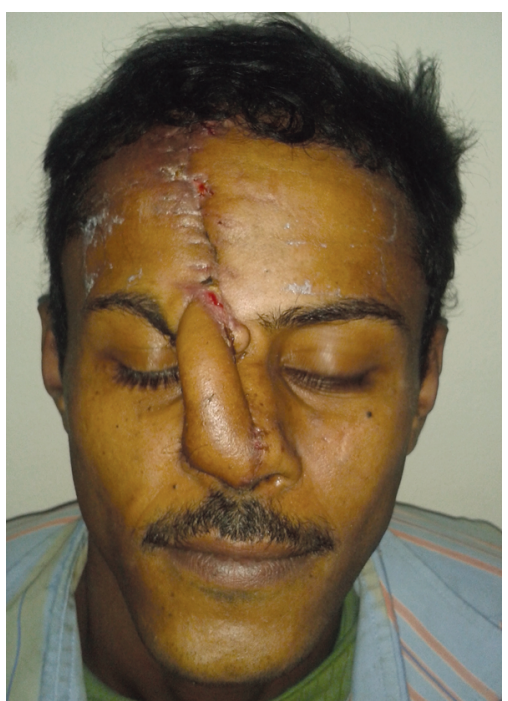

(B)

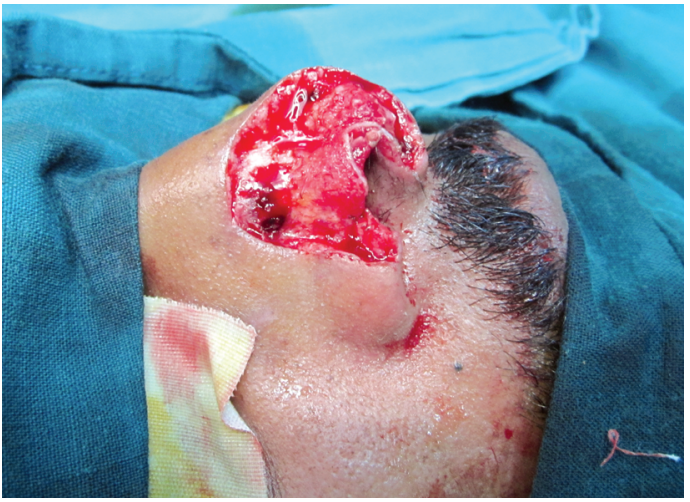

(D)

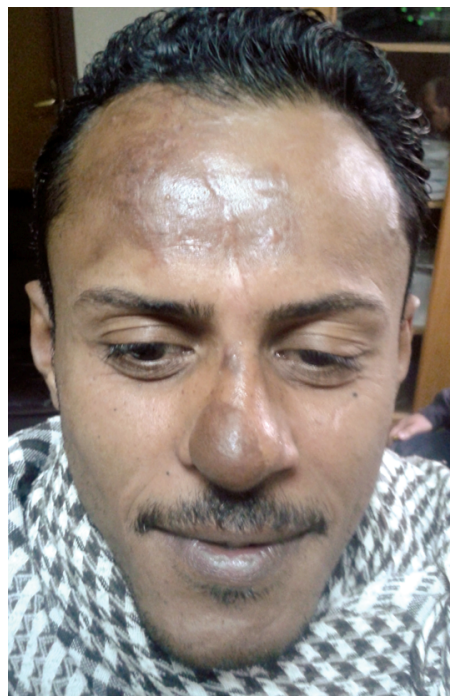

Case (1): Traumatic loss of the lower half of right of right nasal side, reconstruction was done by Midline forehead flap.

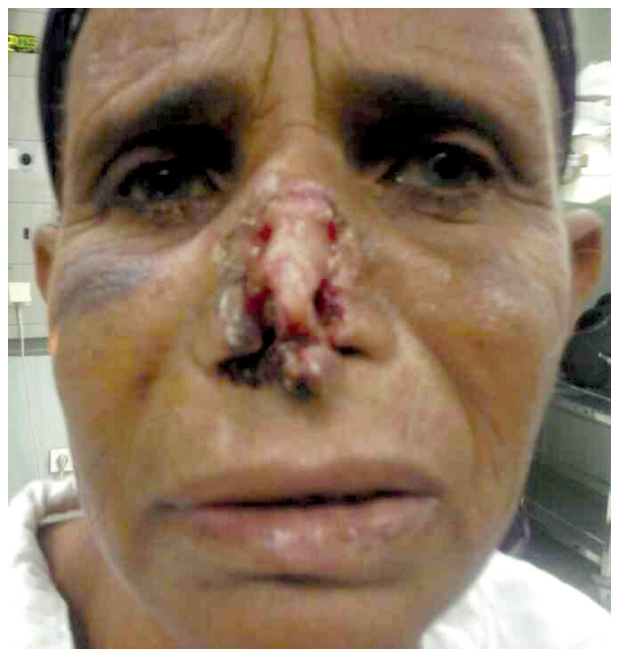

(A)

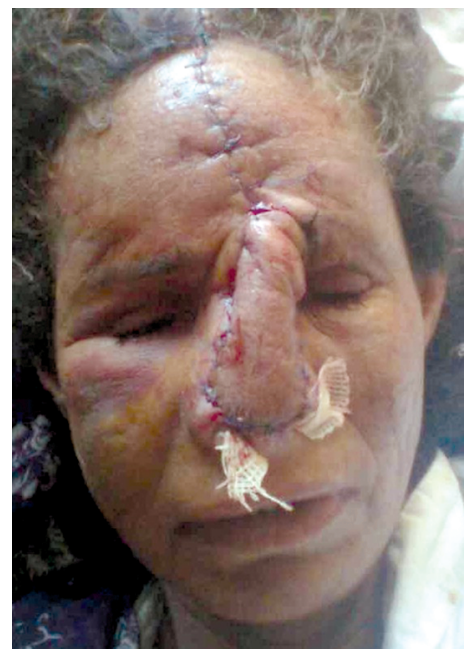

(B)

Case (2): Human bite of the whole front of the nose, reconstruction was done by midline forehead flap. 
(A)

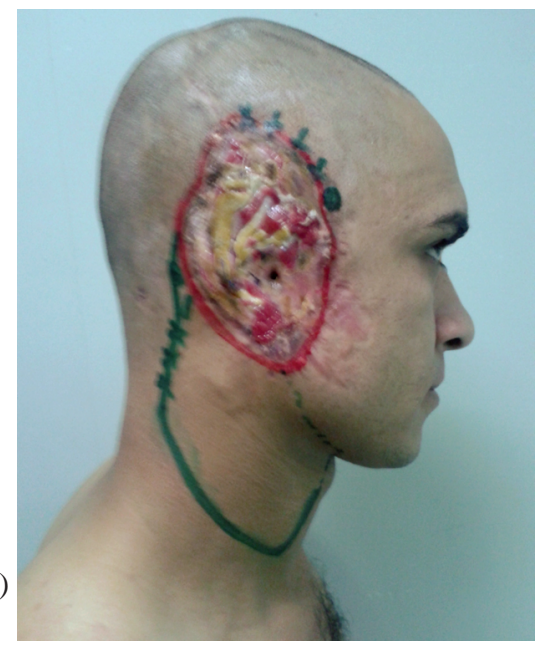

(B)

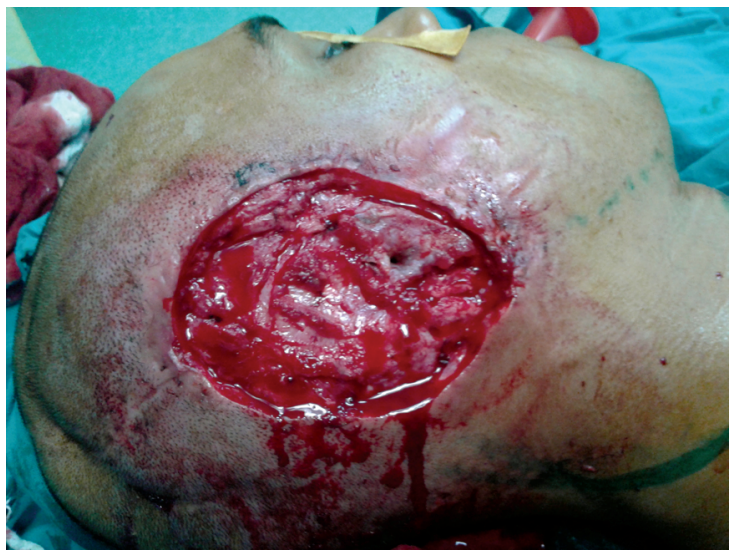

(D)

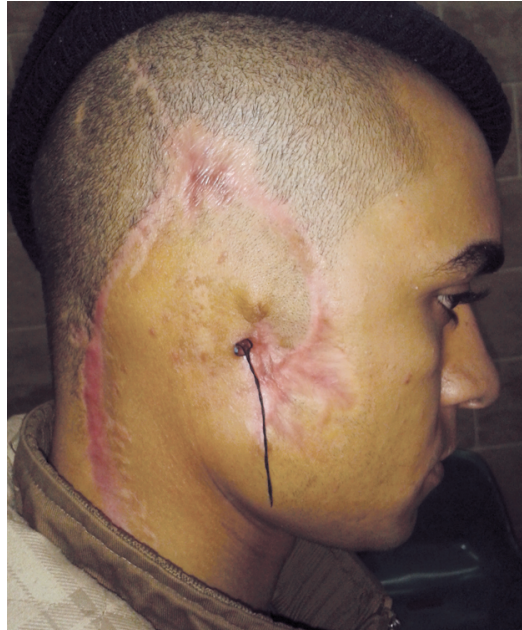

(C)

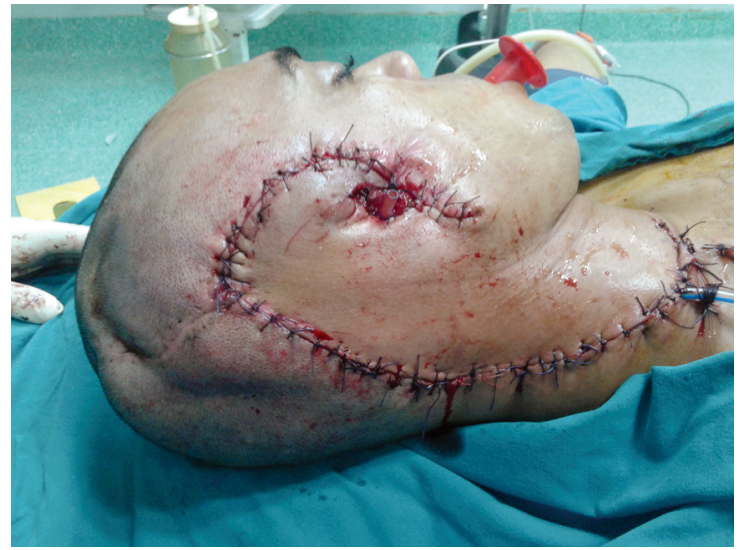

Case (3): Post-traumatic delayed presentation of total loss of right ear and temporal area, reconstruction was done by Cervico-facial flap.
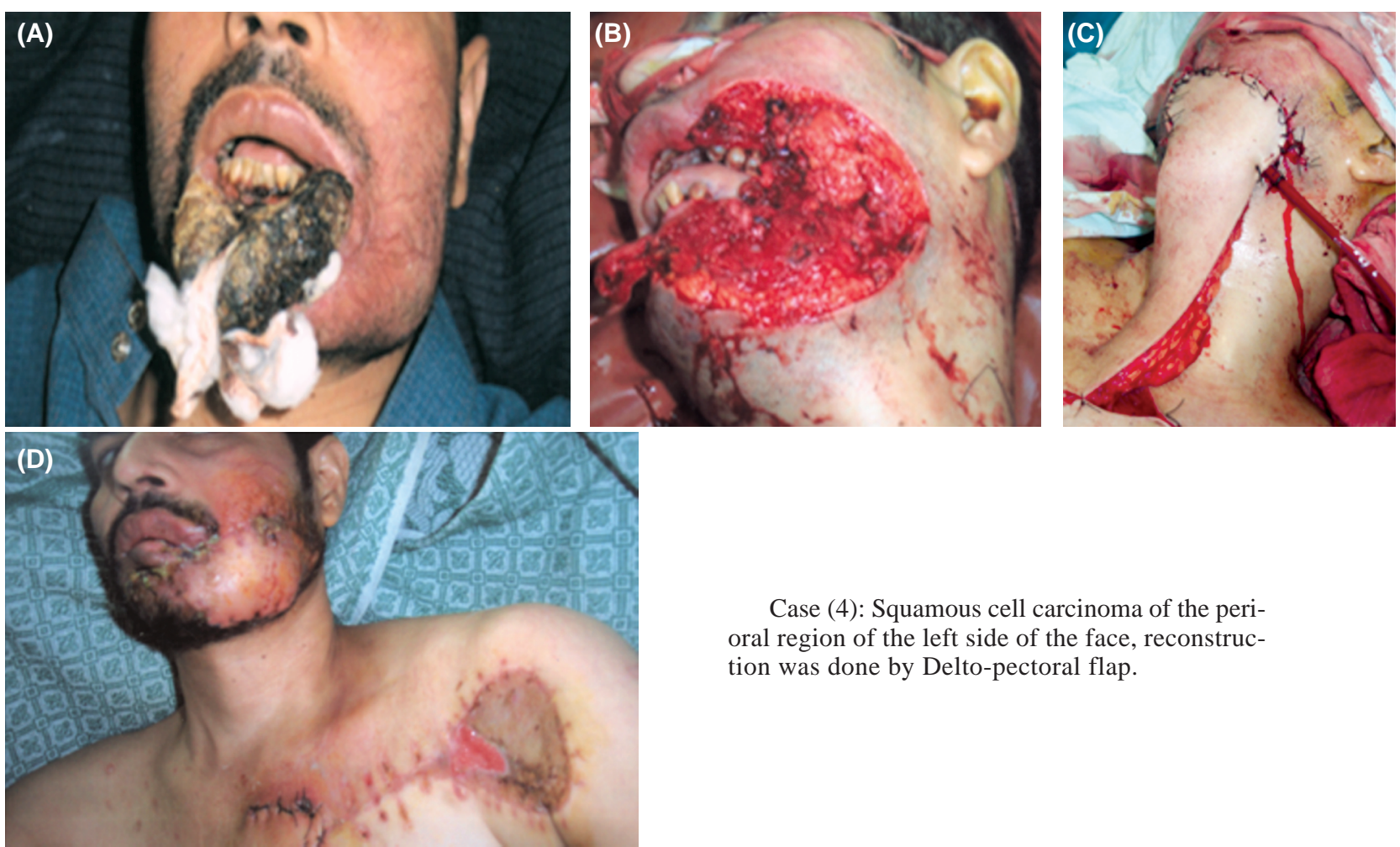

Case (4): Squamous cell carcinoma of the perioral region of the left side of the face, reconstruction was done by Delto-pectoral flap. 


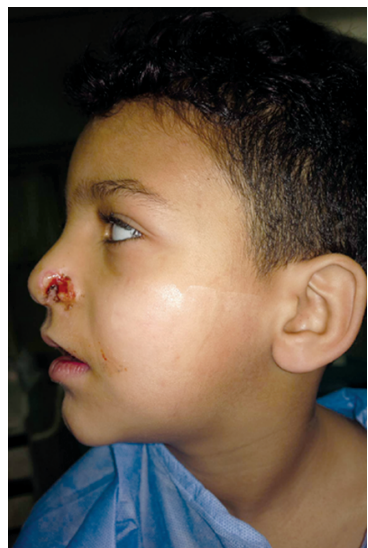

(A)

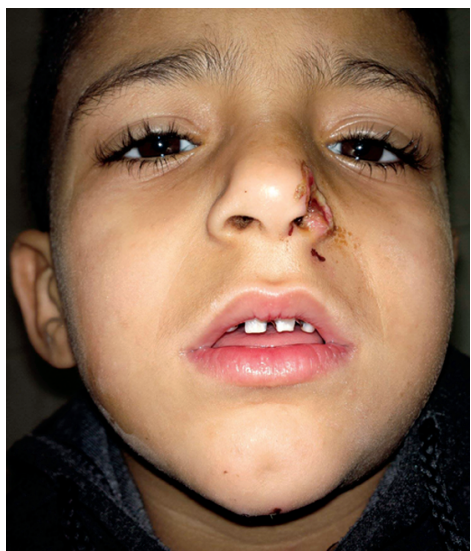

(B)

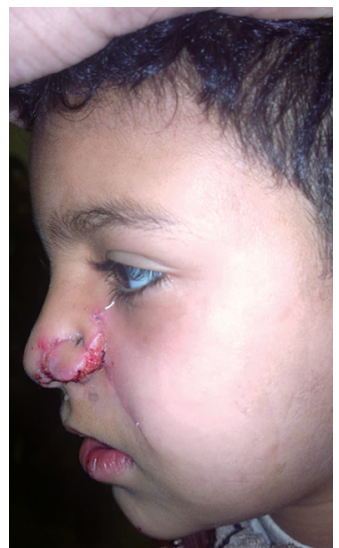

(C)

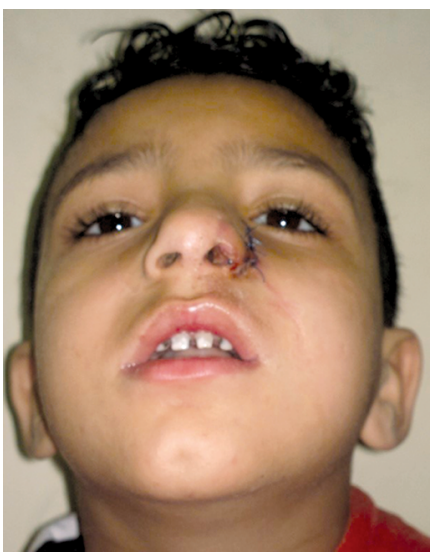

(D)

Case (5): Traumatic loss of the left nasal ala, reconstruction was done by Nasolabial flap.

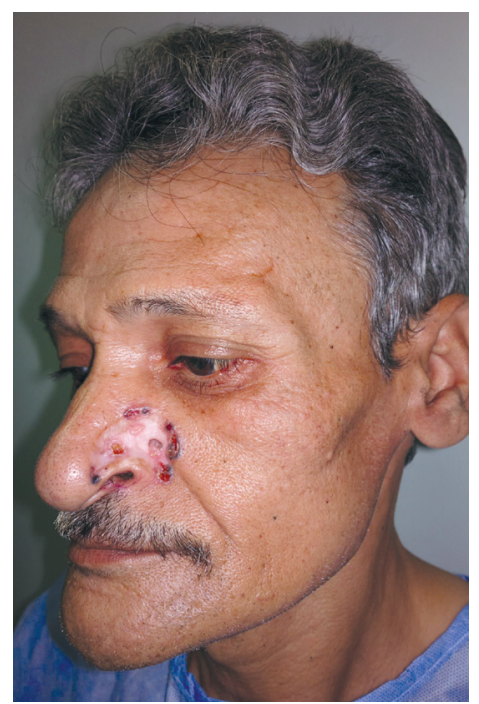

(A)

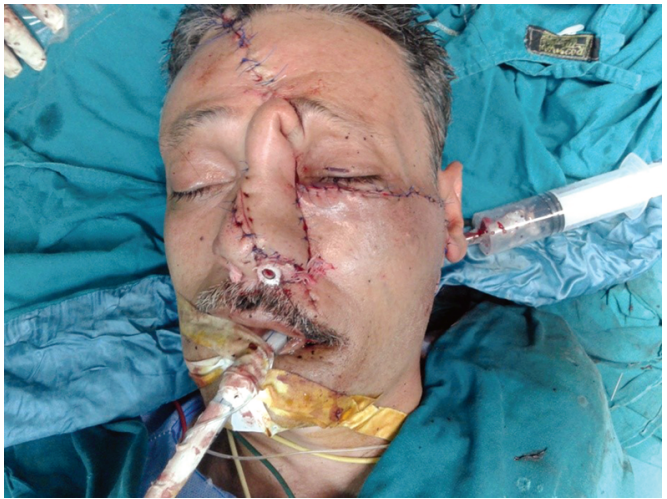

(B)

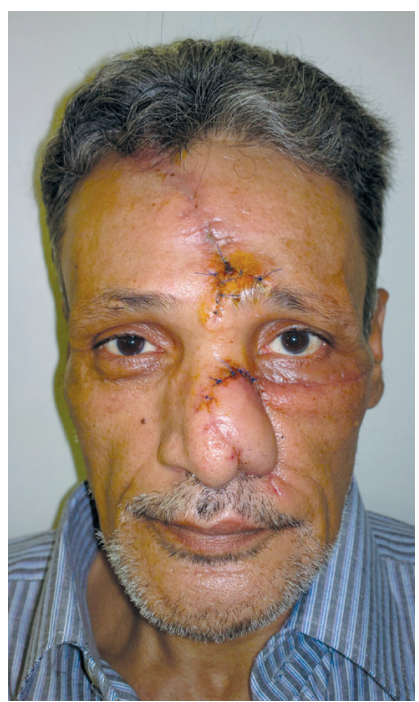

(C)

Case (6): Basal cell carcinoma affecting the left side of the nasal side with part of the cheek, reconstruction was done by midline forehead and cheek advancement flaps.

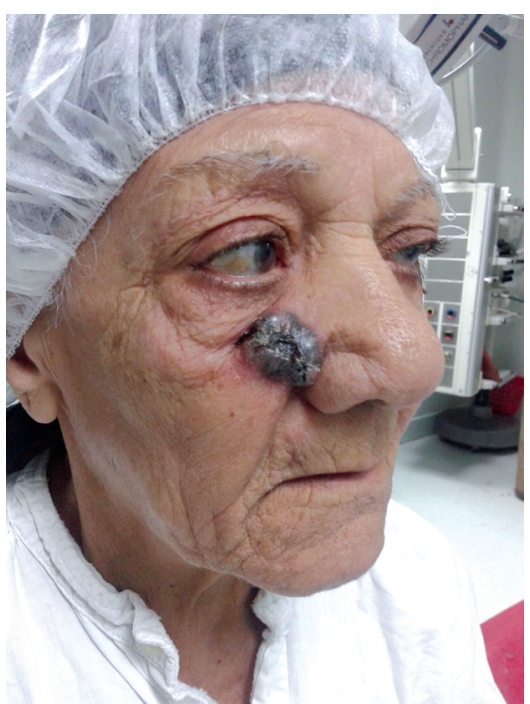

(A)

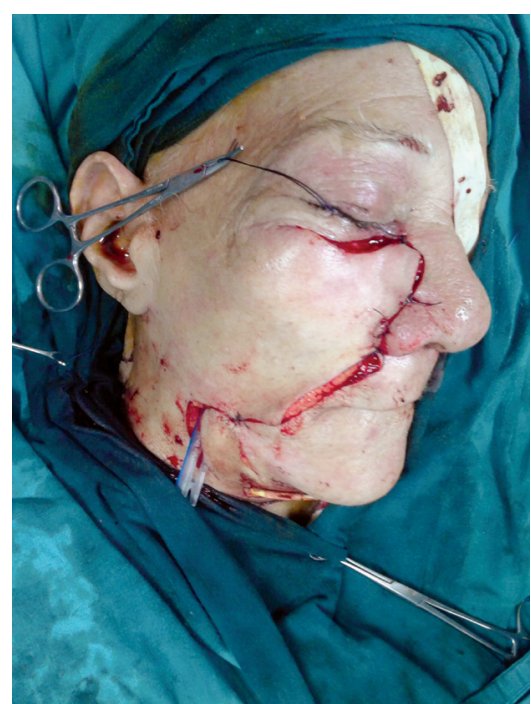

(B)

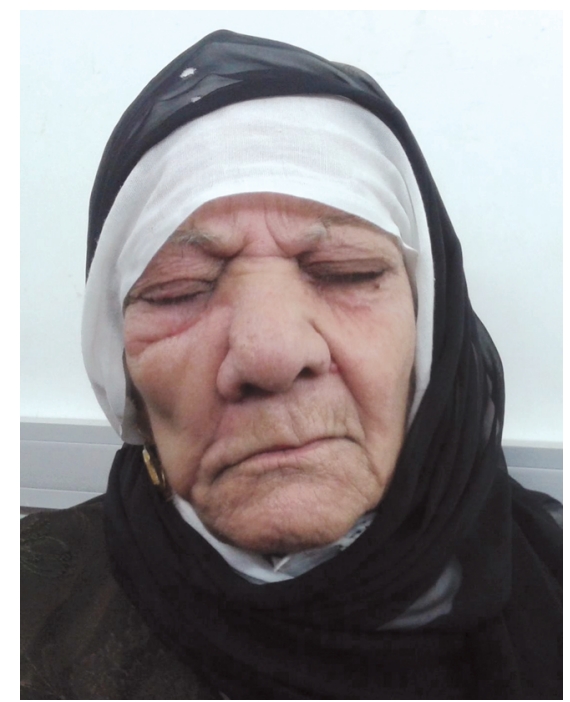

(C)

Case (7): Basal cell carcinoma of the right cheek, reconstruction was done by Cervico-facial flap. 


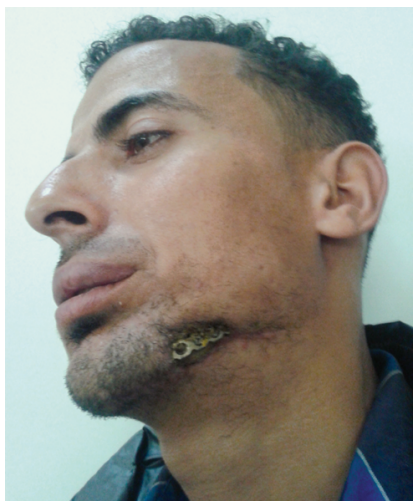

(A)

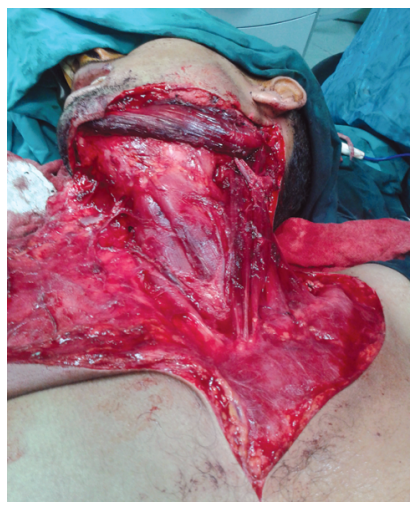

(B)

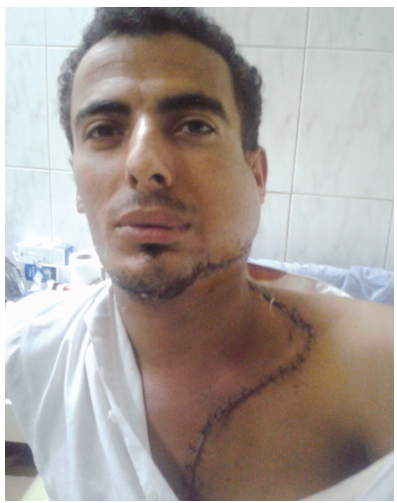

(C)

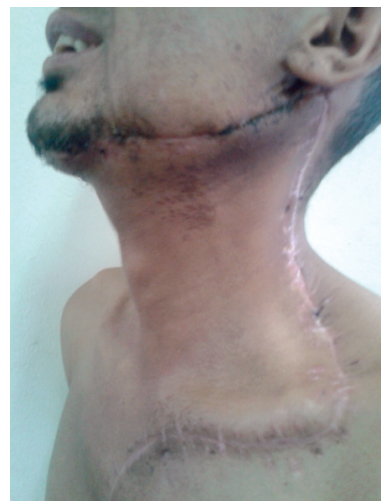

(D)

Case (8): Exposure of reconstruction plate after hemi-mandibulectomy due to mandibular tumour, reconstruction was done by Cervico-pectoral flap.

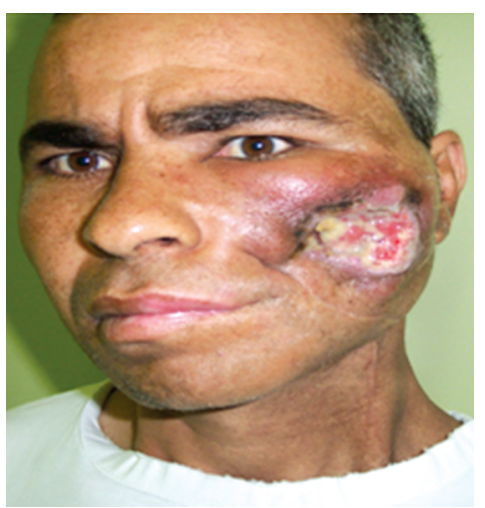

(A)

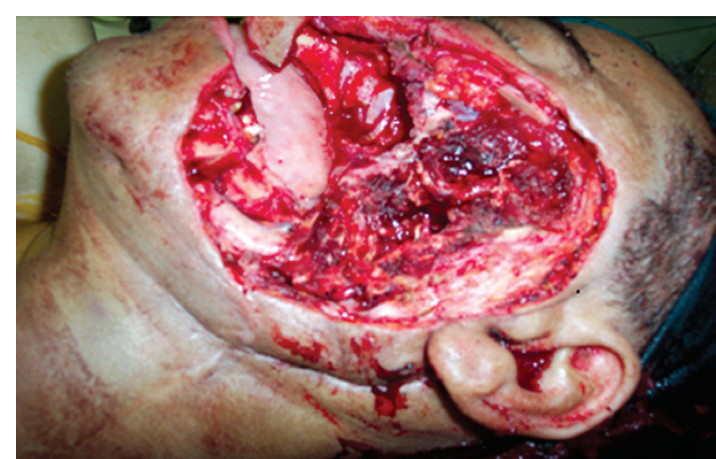

(B)

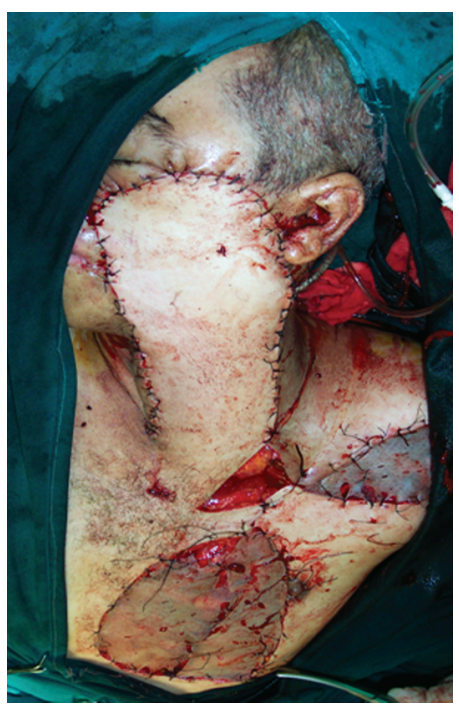

(C)

Case (9): Osteoradionecrosis of the left cheek, Pectoralis major Myocutaneous flap was done.

\section{DISCUSSION}

In our study, 10 defects were successfully reconstructed using Delto-pectoral flaps. Sound healing occurred in 8 of them, while only minor complication occurred in 2 flaps $(20 \%)$, one of them presented with slight dehiscence, while the other one presented with a salivary fistula, both of them treated conservatively. These results conform to the studies of Gilas, et al., Kirkby, et al., and Mendelson, et al., regarding percentage of complications occurred in about 10 to $26 \%$ of their cases $[7,8,9]$.

However, our study agrees more with (Kingdom and Singer), and (Portnoy and Arena) who reported that neither flap necrosis nor partial flap failures occurred in their series, attesting to the reliability of the delto-pectoral flap [10,11].
We believe that limiting the lateral extent of flap design to the acromio-clavicular joint, incorporating a minimum of three (and preferably four) internal mammary perforators at the base of the flap, and maintaining a length-to-width ratio of less than 2:1 are factors that maximize flap reliability and preclude the need for a delay procedure. This conform to the study of Gingrass, et al., who concluded that extension of the random pattern to the axillary based flap may account for some of the distal flap necrosis observed in their series [12].

In our series, defects ranging from $1.5 \mathrm{~cm} \mathrm{x}$ $1.5 \mathrm{~cm}$ to $10 \mathrm{~cm} \times 12 \mathrm{~cm}$ were successfully reconstructed with cervico-facial flaps, and defects ranging from $3 \mathrm{~cm} \times 2 \mathrm{~cm}$ to $12 \mathrm{~cm} \times 8 \mathrm{~cm}$ were successfully reconstructed with cervico-thoracic flaps. The upper boundary of reconstruction with Cervico-facial flap could reach up to the orbital 
area in the midface and up to the temporal lines in lateral aspect of the face, the medial boundary can reach to the midline of the face and the lateral boundary can reach to the pre-auricular or postauricular region. With use of cervico-pectoral flap the reconstruction could reach up to the tragus of the ear superiorly, perioral area medially and postauricular area laterally. The times of harvesting the flaps was not more than 1 hour. This is comparable to the series done by Fa-yu Liu, et al., [13] who could reconstruct defects up to $7 \mathrm{~cm} \times 6 \mathrm{~cm}$ with cervico-facial flaps and defects up to $16 \mathrm{~cm}$ $\mathrm{x} 7 \mathrm{~cm}$ with cervico- flaps.

During our series, we treated 10 patients using cervico-facial and cervico-pectoral flaps. Minor complications occurred only in 3 patients $(30 \%)$. No partial or complete loss of the flaps occurred. This is comparable to the studies of Moore et al., reported that in their cervico-facial flap and cervicothoracic flap series, $31 \%$ experienced some form of wound complication, most often manifested as epidermolysis of the distal skin flap (23\%), while only $(9 \%)$ developed full-thickness necrosis of the distal flap tip [14].

We believe that preservation of superficial cervical fascia, including the superficial veins in the flap, and care not to produce excessive thinning of the skin surrounding the defect are the 3 factors helped to lower our complication rates.

In our series, 6 defects were successfully reconstructed using pectoralis major myo-cutaneous flap (PMMF). The overall flap related complications were $50 \%$ ( 3 patients) 2 patients had minor complications in the form of epidermolysis, while one patient had a moderate complication in the form of loss of the terminal $1 \mathrm{~cm}$ of the flap, both were treated conservatively with dressings. No total flap loss occurred in any patient. This agrees with various studies showed that reported complications varies from $17 \%$ to $63 \%$ [15-18].

Also, our results are comparable with the results of Tripathi et al., who observed a complication rate of $40 \%$ with $16 \%$ occurrence of flap necrosis. Major flap necrosis occurred in 6\% with no incidence of total flap necrosis [19].

Our results agree with Mc Lean et al., that one major advantage of PMMC flaps is survival. Even in hands of an experienced microsurgeon total flap necrosis occur in free flap reconstructions; however, total loss of PMMC flaps is uncommon [20].

In our study we used nasolabial flaps to reconstruct 7 defects with diameters between $1.5 \mathrm{~cm}$ and
$2.0 \mathrm{~cm}$ and involving the alar lobules and lower third of the nose with good roundness of the alae. This agrees with the studies of (Zitelli), (Zitelli and Fazio), and (Belmahi et al.) who reported that the nasolabial fold can supply enough skin to resurface the ala $[\mathbf{2 1}, \mathbf{2 2}, 23]$ and the contractility of the nasolabial flap can be used to simulate the round, expected bulge of the normal ala [23].

In our series all the nasolabial flaps were healthy without any complication. This conform to the study Jagdeep and Kaustubh, who showed the same results [24].

During our study, 10 defects involving the nose were reconstructed using midline forehead flap. All patients accomplished successful nasal resurfacing although 2 patient suffered minor complication in the form of epidermolysis along the distal $2-\mathrm{mm}$ border of the skin paddle. This area was treated conservatively and re-epithelialized uneventfully. No flaps suffered full-thickness necrosis or congestion that required intervention.

This conform to the results of Stephen and park, who repaired 10 patients with single stage forehead flap reconstruction and only 1 patient suffered epidermolysis while the rest of patients passed uneventful postoperative period [25].

We also agree with Millard, who stated that for nasal reconstructions, the midline forehead skin flap can serve as a cover for any nasal reconstruction from severe tip and ala loss to a total nasal defect. Using this flap, aesthetic and functional reconstruction can be achieved by creating a nose that blends well with the face [26].

It appears that in the recent history of head and neck reconstruction, pedicled and free flaps have concurred for the same indications and that their use, in some cases, can be mutually exclusive. Still, free flaps are considered the reference standard for many cases of head and neck reconstruction; however, a significant body of data has been increasing slowly but steadily in which pedicled flaps have been used in comparable settings. In many instances, pedicled regional or microvascular soft tissue flaps compete for the same indication, each technique with its advantages and disadvantages [4].

Comparing different case series with each other can only provide an idea of flap reliability. Also, if we compare these case series, it appears that pedicled and free flaps are equally reliable $[\mathbf{2 7 , 2 8}]$. 
From all the previous observations and studies we conclude that with the use of regional flaps we can successfully manage different facial defects with good results and mild complications. Also we agree that even in the presence of free flap reconstructions, the regional flaps still have a great rule and still compete with the free flaps in reconstruction of the face.

Evolving reconstructive techniques have greatly advanced to approach the facial reconstruction. During our study, we could reconstruct difficult facial defects with a number of regional flaps with good success showing that these flaps are versatile options in facial reconstruction.

\section{Conclusion:}

Facial defects can frequently be managed with the correct choice of the regional flap. Probably, the flaps in the vicinity of an area provide the best result due to the good matching of the skin in terms of colour, texture, and thickness and adhere to one of the basic principles in plastic surgery "Replace like with like". Also, despite the increasing use of free flaps, regional flaps are still a valid and safe option for head and neck reconstruction that allow good aesthetics and functional outcomes.

\section{REFERENCES}

1- Lior H., Patrick C. and Yoav K.: Cheek Reconstruction: Current Concepts in Managing Facial Soft Tissue Loss, Semin. Plast. Surg. Nov., 22 (4): 294-305. doi: 10.1055/s0028-1095888, 2008.

2- Behnia H. and Motamedi M.H. Reconstruction and rehabilitation of short-range, high-velocity gunshot injury to the lower face: A case report. J. Craniomaxillofac. Surg., 25 (4): 220-7, 1997.

3- Miloro M.: Peterson's Principals of Oral and Maxillofacial Surgery, 2nd ed. London: BC Decker, 2004.

4- Giacomo C., Karim T., Alessandro B., Fabiana A., Matteo C., Marco M. and Dimitri R.: Regional Flaps in Head and Neck Reconstruction: A Reappraisal Journal of Oral and Maxillofacial Surgery, 73 (3): March 2015.

5- Fernandes R.: Cervicofacial Advancement Flap, in Local and Regional Flaps in Head \& Neck Reconstruction: A Practical Approach, John Wiley \& Sons, Inc., Hoboken, NJ, USA. doi: 10.1002/9781118947272.ch13, 2014.

6- Burget G.C. and Menick F.J.: The subunit principle in nasal reconstruction. Plast. Reconstr. Surg., 76239- 247, 1985.

7- Gilas T., Sako K., Razack M.S., Bakamjian V.Y., Shedd D.P. and Calamel P.M.: Major head and neck reconstruction using the deltopectoral flap: A 20 year experience. Am. J. Surg., 152: 430, 1986.

8- Kirkby B., Krag C. and Siemssen O.J.: Experience with the deltopectoral flap. Scand. J. Plast. Reconstr. Surg., 14: $151,1980$.
9- Mendelson B.C., Woods J.E. and Masson J.K.: Experience with the deltopectoral flap. Plast. Reconstr. Surg., 59: $360,1977$.

10- Kingdom T.T. and Singer M.I.: Enhanced reliability and renewed applications of the deltopectoral flap in head and neck reconstruction. Laryngoscope, 106: 1230, 1996.

11- Portnoy W.M. and Arena S.: Deltopectoral island flap. Otolaryngol. Head Neck Surg., 111: 63, 1994.

12- Gingrass R.P., Culf N.K., Garrett W.S., Jr. and Mladick R.A.: Complications with the deltopectoral flap. Plast. Reconstr. Surg., 49: 501, 1972.

13- Fa-yu L., Zhong F.X., Peng L., Chang-Fu S., Rui-Wu L., Shu-Fen G., Jun-lin L., Shao-Hui H. and Xuexin T.: The versatile application of cervicofacial and cervicothoracic rotation flaps in head and neck surgery. World Journal of Surgical Oncology, 9: 135, DOI: 10.1186/1477-7819-9135, 2011.

14- Moore B.A., Wine T. and Netterville J.L.: Cervicofacial and cervicothoracic rotation flaps in head and neck reconstruction. Head Neck, 27: 1092-1101, 2005.

15- Croce A., Moretti A., D'Agostino L. and Neri G.: Continuing validity of pectoralis major muscle flap 25 years after its first application. Acta. Otorhinolaryngol. Ital., 23: 297-304. [PubMed], 2003.

16- Liu R., Gullane P., Brown D. and Irish J.: Pectoralis major myocutaneous pedicled flap in head and neck reconstruction: Retrospective review of indications and results in 244 consecutive cases at the Toronto General Hospital. J. Otolaryngol., 30: 34-40. [PubMed], 2001.

17- Shah J.P., Haribhakti V., Loree T.R. and Sutaria P.: Complications of the pectoralis major myocutaneous flap in head and neck reconstruction. Am. J. Surg., 160: 352-5, 1990.

18- Vartanian J.G., Carvalho A.L., Carvalho S.M., Mizobe L., Magrin J. and Kowalski L.P.: Pectoralis major and other myofascial/myocutaneous flaps in head and neck cancer reconstruction: Experience with 437 cases at a single institution. Head Neck, 26: 1018-23, 2004.

19- Mayank Tripathi,1 Sanjeev Parshad,2 Rajender Kumar Karwasra,1,2 and Virender Singh3: Pectoralis major myocutaneous flap in head and neck reconstruction: An experience in 100 consecutive cases. Natl. J. Maxillofac. Surg. Jan-Jun., 6 (1): 37-41, 2015.

20- McLean J.N., Carlson G.W. and Losken A.: The pectoralis major myocutaneous flap revisited: A reliable technique for head and neck reconstruction. Ann. Plast. Surg., 64: 570-3, 2010.

21- Zitelli J.A.: The nasolabial flap as a single-stage procedure. Arch. Dermatol., 126: 1445-8. [PubMed], 1990.

22- Zitelli J.A. and Fazio M.J.: Reconstruction of the nose with local flaps. J. Dermatol. Surg. Oncol., 17: 184-9. [PubMed], 1991.

23- Belmahi A., El Mazouz S., Gharib N.E., Bencheikh R. and Ouazzani S.: The bilobed flap: A very efficient method in aesthetic reconstruction of small skin defects at the alar and tip regions of the nose. Ann. Chir. Plast. Esthet., 48: 211-5, 2003. 
24- Jagdeep K. and Kaustubh S.S.: Overview of Local Flaps of the Face for Reconstruction of Cutaneous Malignancies: Single Institutional Experience of Seventy Cases. J. Cutan Aesthet. Surg. Oct-Dec., 9 (4): 220-225, 2016.

25- Stephen S. and Park, M.D.: The Single-Stage Forehead Flap in Nasal Reconstruction an Alternative with Advantages. Arch. Facial Plast. Surg., 4 (1): 32-36, 2002.

26- Millard D.R.: In: Midline forehead skin flap. Grabb's Encyclopedia of Flaps. Berish S., editor. Vol. 1. Philadel- phia, PA, USA: Lippincott Williams \& Wilkins, pp. 99100, 2009.

27- Gadre K.S., Gadre P., Sane V.D., et al.: Pectoralis major myocutaneous flap Still a workhorse for maxillofacial reconstruction in developing countries. J. Oral Maxillofac. Surg., 71: 2005.e1, 2013.

28- Hsing C.Y., Wong Y.K., Wang C.P., et al.: Comparison between free flap and pectoralis major pedicled flap for reconstruction in oral cavity cancer patients A quality of life analysis. Oral Oncol., 47: 522, 2011. 